\title{
Duração da imunidade passiva para lentivírus de pequenos ruminantes em cordeiros
}

\section{Duration of passive immunity to small ruminant lentiviruses in lambs}

\author{
Thiago Sampaio de Souza ${ }^{1 *}$; Joselito Nunes Costa ${ }^{2}$; Raymundo Rizaldo Pinheiro ${ }^{3}$; \\ Carla Caroline Valença de Lima ${ }^{1}$; Fabio Carreiro Chaves de Melo ${ }^{4}$; Alice Andrioli ${ }^{5}$; \\ Dalva Alana Aragão de Azevedo ; Vanderlan Warlington Souza dos Santos ${ }^{6}$; \\ Eduardo Luiz de Oliveira ${ }^{7}$; Antonio de Oliveira Costa Neto ${ }^{8}$
}

\begin{abstract}
Resumo
Com a finalidade de avaliar a imunidade passiva contra lentivírus de pequenos ruminantes (LVPR), em cordeiros, este estudo foi conduzido a partir de dois grupos experimentais. O primeiro (G1) foi estabelecido por nove cordeiros submetidos à mamada artificial de pool de colostro de cabras positivas para LVPR. O segundo (G2) foi o controle, constituído por dez cordeiros submetidos à mamada natural de colostro das suas mães negativas. Amostras de sangue foram obtidas antes da primeira mamada, após $24 \mathrm{~h}$ do nascimento e com sete, 15, 30, 50, 70, 90 e 120 dias de vida. Determinaram-se as concentrações de proteína sérica total (PST), albumina (ALB), globulinas (GLOB) e imunoglobulina $\mathrm{G}(\mathrm{IgG})$ e anticorpos anti-LVPR foram pesquisados a partir das técnicas de imunodifusão em gel de agarose (IDGA), ensaio imunoadsorvente ligado à enzima (Elisa) e immunoblotting (IB). Em ambos os grupos, as menores médias de PST, GLOB e IgG foram observadas ao nascimento e as maiores médias foram constatadas às 24 horas de vida, devido à absorção de imunoglobulinas colostrais. Para o G1, a transferência de imunidade também pôde ser constatada pelas provas de imunodiagnóstico. Ao nascimento, os animais estavam soronegativos. Com 24 horas, todos foram reagentes nos três testes sorológicos. Posteriormente, resultados negativos começaram a ser observados, a partir dos 15 dias de idade, pela prova de IDGA. Já pelo teste de Elisa, todos os animais permaneceram reagentes até os 50 dias de vida. Apenas o IB foi capaz de detectar anticorpos anti-LVPR aos 70 dias. Em relação ao G2, todos os animais apresentaram resultados negativos nos testes de IDGA e IB, do nascimento aos 120 dias de idade. Entretanto, resultados falso-positivos foram observados até os 15 dias nos testes de Elisa, devido a reações inespecíficas. Esses dados estão de acordo com a sensibilidade e especificidade de cada prova sorológica e demonstram que a partir de 90 dias de idade, anticorpos colostrais anti-LVPR não mais são detectados no soro de cordeiros.
\end{abstract}

Palavras-chave: Anticorpos colostrais, imunodiagnóstico, lentiviroses, ovinos

\footnotetext{
${ }^{1}$ Discentes de Pós-Graduação, Universidade Federal da Bahia, UFBA, Salvador, BA. E-mail: thiago_sampaio@hotmail.com; carlacvlima@gmail.com

2 Prof. da Universidade Federal do Recôncavo da Bahia, UFRB, Cruz das Almas, BA. E-mail: joselitonc@yahoo.com.br

${ }^{3}$ Pesquisador, Empresa Brasileira de Pesquisa Agropecuária, Embrapa, Sobral, CE. E-mail: rizaldo.pinheiro@embrapa.br

${ }^{4}$ Prof. do Instituto Centro de Ensino Tecnológico, Centec, Nova Russas, CE. E-mail: fabioccmelo@gmail.com

${ }^{5}$ Pesquisadora, Empresa Brasileira de Pesquisa Agropecuária, Embrapa, Sobral, CE. E-mail: alice.andrioli@embrapa.br

${ }^{6}$ Discentes de Pós-Graduação, Universidade Estadual do Vale do Acaraú, UVA, Sobral, CE. E-mail: dalvaazevedo@outlook.com; vanderlansouza@zootecnista.com.br

${ }^{7}$ Analista, Empresa Brasileira de Pesquisa Agropecuária, Embrapa, Sobral, CE. E-mail: eduardo.luiz@embrapa.br

${ }^{8}$ Prof. da Universidade Estadual de Feira de Santana, UEFS, Feira de Santana, BA. E-mail: aocneto@hotmail.com

* Autor para Correspondência
} 


\begin{abstract}
In order to evaluate the passive immunity against small ruminant lentiviruses (SRLV) in lambs, this study was conducted from two experimental groups. The first one (G1) was established by nine lambs subjected to artificial feeding of colostrum of goats positive for SRLV. The second one (G2) was the control group, consisting of ten lambs subjected to suckling of colostrum from their negative mothers. Blood samples were obtained before the first feeding, after 24 hours of birth and at 7, 15, 30, 50, 70, 90 and 120 days of age. The concentrations of total serum protein (TSP), albumin (ALB), globulin (GLOB) and immunoglobulin $\mathrm{G}(\mathrm{IgG})$ were determined and antibodies to SRLV were surveyed from the techniques of agar gel immunodiffusion (AGID), enzyme linked immunosorbent assay (Elisa) and immunoblotting (IB). In both groups, the lowest averages of TSP, GLOB and IgG were observed at birth and the highest averages were observed at 24 hours of life, due to absorption of colostral immunoglobulins. For G1, transfer of immunity could also be detected by immunodiagnostic tests. At birth, the animals were seronegative. After 24 hours, all animals were positive in three serological tests. Negative results began to be observed after 15 days of age by the AGID test. As for Elisa testing, all animals remained reagent until 50 days old. Only IB was able to detect anti-SRLV at 70 days. Regarding G2, all animals tested negative in AGID and IB, from birth until 120 days of age. However, false-positive results were observed until day 15 in Elisa, due to nonspecific reactions. These data are consistent with the sensitivity and specificity of serological tests and show that starting at 90 days of age, colostral antibodies to SRLV are no longer detected in the serum of lambs.
\end{abstract}

Key words: Colostral antibodies, immunodiagnostic, lentiviruses, sheep

\section{Introdução}

Durante a evolução das espécies, mecanismos de transferência de imunidade da mãe para a prole se desenvolveram para que toda experiência imunológica materna protegesse o filho após o nascimento. Em mamíferos, imunoglobulinas podem ser adquiridas passivamente pelo recémnascido, através da placenta ou por meio da ingestão de colostro (HURLEY; THEIL, 2011).

No caso dos ruminantes, a placenta do tipo sindesmocorial impede a passagem de proteínas séricas de alto peso molecular, como as imunoglobulinas, da circulação materna para a fetal (FEITOSA, 1999). Por isso, o recém-nascido ruminante é desprovido de anticorpos, adquirindoos somente após a ingestão de colostro (BORGES et al., 2001; SIMÕES et al., 2005; SILVA et al., 2007; SILVA et al., 2010).

Logo, o monitoramento da transferência de imunidade é uma medida que pode refletir na redução das taxas de morbidade e mortalidade neonatais em rebanhos ovinos (SILVA et al., 2010), já que a inadequada ingestão de colostro está entre as principais causas de morte em cordeiros no período perinatal (NÓBREGA JÚNIOR et al., 2005). Além disso, a quantidade e qualidade, bem como a precocidade no fornecimento, são fundamentais para a aquisição de bons níveis de imunoglobulinas (SIMÕES et al., 2005; YANAKA et al., 2012).

Por outro lado, a ingestão de colostro e leite pode ser uma importante forma de transmissão de agentes infecciosos, como lentivírus de pequenos ruminantes (LVPR) (LARA et al., 2003; PREZIUSO et al., 2004; ÁLVAREZ et al., 2005). Estes são retrovírus não oncogênicos (STRAUB, 2004), que infectam principalmente monócitos e macrófagos (GENDELMAN et al., 1986), provocando enfermidades de curso progressivo, denominadas de artrite-encefalite caprina (CAE) em caprinos e maedi-visna (MV) em ovinos (PASICK, 1998; CALLADO; CASTRO; TEIXEIRA, 2001; SOUZA et al., 2012).

Em programas de sanidade de pequenos ruminantes, uma das alternativas adotadas para o controle e prevenção dos LVPR é a termização do colostro a $56^{\circ} \mathrm{C}$ durante uma hora, para destruição das partículas virais (DAWSON, 1987). Este 
método não prejudica a qualidade do colostro para a transferência de imunidade, mas deve-se atentar para a presença de anticorpos anti-LVPR, que serão transferidos, tornando os animais reagentes após a mamada, o que compromete a utilização de testes sorológicos para o diagnóstico (SILVA et al., 2007). Ressalta-se ainda que os anticorpos colostrais anti-LVPR não previnem a infecção dos neonatos (ÁLVAREZ et al., 2005; ÁLVAREZ et al., 2006).

Logo, o objetivo deste trabalho foi constatar a transferência de imunidade passiva contra lentivírus de pequenos ruminantes, em cordeiros, avaliando-se a duração da resposta imune adquirida e a aplicação de diferentes métodos de imunodiagnóstico.

\section{Material e Métodos}

Para a condução do estudo, grupos experimentais foram constituídos levando-se em consideração o princípio dos “3R's”, que inclui a redução do número de animais em pesquisa científica (Resolução do Conselho Federal de Medicina Veterinária N. 879, de 15 de fevereiro de 2008), estando de acordo com os princípios éticos adotados pelo Conselho Nacional de Controle de Experimentação Animal CONCEA (Lei n ${ }^{\circ} 11.794$, de 8 de outubro de 2008), com aprovação da Comissão de Ética no Uso de Animais da Universidade Estadual Vale do Acaraú (CEUA/UVA), sob o número 001.12.

Os cordeiros que constituíram os grupos foram filhos de matrizes e reprodutores de rebanho ovino livre de LVPR e ainda assim testado previamente por imunodifusão em gel de agarose (IDGA), ensaio imunoadsorvente ligado à enzima (Elisa) e immunoblotting (IB), com resultados negativos para todas as provas, em quatro diferentes momentos.

O primeiro grupo (G1) foi estabelecido por nove cordeiros submetidos à mamada artificial exclusiva de pool de colostro de cabras positivas para LVPR, durante as primeiras 24 horas de vida. A quantidade de colostro fornecida foi de aproximadamente $11 \%$ do peso vivo nas primeiras oito horas pós-parto, visando à adequada transferência de imunidade passiva (NÓBREGA JÚNIOR et al., 2005; SIMÕES et al., 2005; YANAKA et al., 2012). Mamadas adicionais ainda foram oferecidas até 24 horas após o nascimento, quando então os animais começaram a mamar diretamente nas suas mães. Durante esse período de 24 horas após o parto, as ovelhas tiveram o úbere ordenhado e os tetos isolados para impedir a mamada natural. O segundo grupo (G2) foi o controle, constituído por dez cordeiros, que mamaram colostro naturalmente das suas mães negativas, havendo apenas o monitoramento das mamadas, conforme metodologia descrita por Silva et al. (2010).

Cada grupo permaneceu isolado em sistema de confinamento, recebendo alimentação volumosa e concentrada em cocho, além de água à vontade e suplementação mineral. Todos os cordeiros foram monitorados clinicamente, através de exame físico, hemograma e parasitológico de fezes, como forma de manejo sanitário. Aos 90 dias de vida, houve o desmame.

Amostras de sangue foram obtidas antes da primeira mamada e com 24h, sete, 15, 30, 50, 70, 90 e 120 dias de vida, por venopunção da jugular, com antissepsia, em sistema a vácuo, utilizando-se tubos sem anticoagulante. Após formação de coágulo, os tubos foram centrifugados a $1.500 \mathrm{~g}$, por 10 minutos, acondicionando-se o soro a $-20^{\circ} \mathrm{C}$.

Nas amostras coletadas até os primeiros 30 dias de vida, foram determinadas as concentrações ( $\mathrm{g} /$ dL) de proteína sérica total (PST) e albumina (ALB), pelos métodos colorimétricos de reação com $\mathrm{o}$ biureto e do verde de bromocresol, respectivamente, a partir de kits comerciais (Labtest ${ }^{\circledR}$ ), seguindo-se as recomendações do fabricante. $\mathrm{O}$ teor $(\mathrm{g} / \mathrm{dL}) \mathrm{de}$ globulinas (GLOB) foi calculado pela diferença entre PST e ALB (SILVA et al., 2007). Também foram determinadas as concentrações séricas $(\mathrm{g} /$ dL) de imunoglobulinas $\mathrm{G}$ ( $\mathrm{IgG}$ ) utilizando-se kit comercial de Elisa (Bethyl Laboratories ${ }^{\circledR}$ ), conforme manual técnico do fabricante. Analisaram-se os 
dados com auxílio do programa Statistica versão 7.1 (STATISTICA, 2005). A Prova de Wilcoxon foi aplicada para identificar diferenças significativas entre as médias das variáveis nos momentos analisados e a Prova de Mann-Whitney foi utilizada para verificar diferenças significativas entre as médias dos grupos experimentais. Todas as análises tiveram como referência $95 \%$ de confiança $(p<0,05)$.

No intuito de pesquisar anticorpos anti-LVPR, os testes de IDGA, Elisa e IB foram aplicados. Para tanto, produziu-se antígeno a partir de cultivos secundários de membrana sinovial caprina (MSC), inoculados com cepa padrão CAEV Cork (PINHEIRO et al., 2006; PINHEIRO et al., 2010). No teste de IDGA, utilizou-se antígeno concentrado por ultrafiltração e tratado com éter etílico (PINHEIRO et al., 2010). Para o Elisa, o antígeno empregado foi obtido a partir de pellet de células tratado com dodecil sulfato de sódio (SDS), conforme metodologia descrita por Torres et al. (2009). Já na técnica de IB, valeu-se de antígeno produzido por ultracentrifugação em colchão de sacarose (PINHEIRO et al., 2006).

Os testes de IDGA foram realizados em placas de petri plásticas $(90 \times 15 \mathrm{~mm})$, contendo $13 \mathrm{~mL}$ de gel de agarose a $1 \%$ em solução salina fosfatada (PBS). Após a perfeita polimerização, o gel foi perfurado com roseta metálica hexagonal, formando sete poços com capacidade para $25 \mu \mathrm{L}$. O poço central recebeu antígeno e os poços periféricos foram preenchidos com soros a serem testados e soro padrão positivo, de forma intercalada. As placas foram acondicionadas em câmara úmida, a $25^{\circ} \mathrm{C}$. Efetuaram-se leituras com 48 e 72 horas, sobre fonte de luz com fundo escuro, observando-se a formação de linhas de precipitação (PINHEIRO et al., 2005; PINHEIRO et al., 2010). Considerou-se positivo o soro cuja linha de precipitação apresentou identidade com a linha formada pelo soro padrão e negativo aquele que não levou à formação de linha de precipitação ou a linha formada não apresentou identidade com a do soro padrão (ABREU et al., 1998).
Os testes de Elisa foram conduzidos baseandose na metodologia descrita por Pinheiro et al. (2006) e Lima et al. (2013), utilizando-se microplacas rígidas com 96 poços (Nunc-Immuno Plate Maxi-Sorp Surface), de alta capacidade de adsorção. A sensibilização foi realizada com $0,5 \mu \mathrm{g}$ de antígeno por poço e os soros a serem testados, bem como o soro padrão positivo e o padrão negativo foram diluídos 1:50 e distribuídos na placa em duplicata. Utilizou-se conjugado anti-IgG marcado com peroxidase na diluição 1:1500. Os resultados expressos em densidade óptica (DO) foram convertidos em percentual do resultado médio de duas repetições com soro padrão positivo (percentual de positividade - PP), variando de 0 a $100 \%$. O ponto de corte de $25,35 \%$ foi estabelecido a partir de amostras negativas testadas por IDGA e IB (média dos PP mais três vezes o desvio padrão).

As provas de IB foram realizadas com base na técnica descrita por Pinheiro et al. (2011), com modificações. As proteínas do antígeno, separadas por eletroforese em gel de poliacrilamida (SDSPAGE), foram transferidas para a membrana de nitrocelulose (MN) passivamente (CRUZ et al., 2003). Após o bloqueio, a membrana foi cortada em tiras de $3 \mathrm{~mm}$, para incubação com os soros, na diluição de 1:50. O conjugado anti-IgG marcado com peroxidase foi aplicado na diluição de 1:15000. Consideraram-se como positivos os soros cujas tiras apresentaram reação para o polipeptídeo com peso molecular próximo a $28 \mathrm{kDa}$, tendo-se como parâmetro a tira do soro controle positivo e o padrão de peso molecular de proteínas (OLIVEIRA et al., 2008; SARDI et al., 2012).

Para avaliação dos resultados obtidos pelos testes de imunodiagnóstico, determinaram-se valores epidemiológicos relativos e os dados foram submetidos ao teste qui-quadrado $\left(\mathrm{x}^{2}\right)$, corrigido por Yates, de acordo com metodologia descrita por Thrusfield (2004). 


\section{Resultados e Discussão}

Os valores médios de PST, ALB, GLOB e $\operatorname{IgG}(\mathrm{g} / \mathrm{dL})$, do nascimento aos 30 dias de idade, estão apresentados na Tabela 1. Nos dois grupos, as menores médias de PST, GLOB e IgG foram observadas ao nascimento e as maiores médias foram constatadas em 24 horas de vida, com diferença significativa dos demais valores. A partir daí, houve decréscimo das concentrações. Quanto às dosagens de ALB, para o G1, não houve diferença estatística nos primeiros três momentos. A maior média foi obtida aos 30 dias de idade. Já para o G2, houve discreta diferença dos valores nos primeiros três momentos de coleta. As maiores médias foram obtidas aos 15 e 30 dias, não havendo diferença estatística entre estas.

Tabela 1. Valores médios de proteína sérica total (PST), albumina (ALB), globulinas (GLOB) e imunoglobulinas G (IgG), em g/dL, de cordeiros submetidos à mamada de colostro artificial (G1) e natural (G2).

\begin{tabular}{lcccccc}
\hline \multirow{2}{*}{ Médias (g/dL) } & \multicolumn{5}{c}{ Idade dos cordeiros } \\
\cline { 3 - 7 } & & 0h & $\mathbf{2 4 h}$ & $\mathbf{0 7}$ dias & $\mathbf{1 5}$ dias & 30 dias \\
\hline \multirow{2}{*}{ PST } & G1 & $4,35 \pm 0,73 \mathrm{a} * \mathrm{C}^{* *}$ & $8,95 \pm 4,70 \mathrm{aA}$ & $5,81 \pm 0,80 \mathrm{aB}$ & $5,69 \pm 0,52 \mathrm{aB}$ & $5,74 \pm 0,54 \mathrm{aB}$ \\
& G2 & $4,72 \pm 0,38 \mathrm{aE}$ & $8,88 \pm 1,03 \mathrm{bA}$ & $6,82 \pm 0,54 \mathrm{bB}$ & $6,41 \pm 0,59 \mathrm{bC}$ & $5,97 \pm 0,88 \mathrm{aD}$ \\
\multirow{2}{*}{ ALB } & G1 & $2,30 \pm 0,23 \mathrm{aC}$ & $2,17 \pm 0,52 \mathrm{aC}$ & $2,30 \pm 0,17 \mathrm{aC}$ & $2,73 \pm 0,36 \mathrm{aB}$ & $2,91 \pm 0,35 \mathrm{aA}$ \\
& G2 & $2,37 \pm 0,19 \mathrm{aC}$ & $2,25 \pm 0,22 \mathrm{aD}$ & $2,64 \pm 0,27 \mathrm{bB}$ & $2,92 \pm 0,34 \mathrm{aAB}$ & $3,04 \pm 0,27 \mathrm{aA}$ \\
\multirow{2}{*}{ GLOB } & G1 & $2,05 \pm 0,70 \mathrm{aC}$ & $6,78 \pm 4,25 \mathrm{aA}$ & $3,51 \pm 0,87 \mathrm{aB}$ & $2,95 \pm 0,65 \mathrm{aBC}$ & $2,84 \pm 0,60 \mathrm{aC}$ \\
& G2 & $2,35 \pm 0,30 \mathrm{aE}$ & $6,63 \pm 1,14 \mathrm{aA}$ & $4,18 \pm 0,52 \mathrm{aB}$ & $3,49 \pm 0,45 \mathrm{aC}$ & $2,92 \pm 0,72 \mathrm{aD}$ \\
\multirow{2}{*}{ IgG } & G1 & $0,00 \pm 0,00 \mathrm{aE}$ & $1,30 \pm 0,37 \mathrm{aA}$ & $0,51 \pm 0,07 \mathrm{aB}$ & $0,43 \pm 0,12 \mathrm{aC}$ & $0,29 \pm 0,05 \mathrm{aD}$ \\
& G2 & $0,03 \pm 0,03 \mathrm{bE}$ & $1,09 \pm 0,34 \mathrm{aA}$ & $0,62 \pm 0,14 \mathrm{aB}$ & $0,46 \pm 0,11 \mathrm{aC}$ & $0,21 \pm 0,07 \mathrm{bD}$ \\
\hline
\end{tabular}

*Letras minúsculas iguais na mesma coluna, dentro de cada variável: as médias não apresentam diferenças significativas para os grupos colostro e controle, em cada momento observado, pela prova de Mann-Whitney, a 95\% de confiança.

**Letras maiúsculas iguais na mesma linha: as médias não apresentam diferenças significativas dentro dos momentos observados, pela prova de Wilcoxon, a 95\% de confiança.

Fonte: Elaboração dos autores.

A PST em cordeiros recém-nascidos sofre alterações significativas com o desenvolvimento etário. Ao nascimento, verifica-se a menor concentração, atingindo valor máximo a partir de 24 horas de vida (SILVA et al., 2010). Essa diferença nas concentrações protéicas nas primeiras 24 horas deve-se, quase que exclusivamente, à absorção de imunoglobulinas colostrais (FEITOSA et al., 2001; SIMÕES et al., 2005; SILVA et al., 2007; YANAKA et al., 2012).

Antes da ingestão de colostro, o proteinograma se caracteriza pelo predomínio da fração ALB sobre as GLOB, estas últimas em concentração mínima. Após a ingestão, as frações ALB e alfaglobulina mantêm-se relativamente estáveis, sendo que as betaglobulinas e gamablobulinas apresentam aumento significativo (BORGES et al., 2001). No entanto, após as primeiras 24-72 horas, há decréscimo do valor de PST até os 30 dias de vida, para então ocorrer acréscimo progressivo aos 60 e 90 dias de idade (SILVA et al., 2010). O ponto de concentração mínima até os 30 dias reflete a transição entre a fase de catabolismo das imunoglobulinas adquiridas e o início da produção endógena (PAULETTI et al., 2002; FÉRES et al., 2010).

A concentração sérica de $\operatorname{IgG}$ antes da ingestão do colostro foi inexpressiva ou mesmo indetectável. Por outro lado, valores máximos foram constatados às 24 horas, havendo, a partir daí, decréscimo progressivo, corroborando o que foi relatado por Silva et al. (2007), em cabritos que ingeriram colostro de cabras artificialmente. Estes autores 
verificaram concentração sérica média de $\operatorname{IgG}$, às 24 horas de vida, de $0,749 \mathrm{~g} / \mathrm{dL}$, utilizando a técnica de eletroforese em gel de acrilamida (SDS-PAGE) e de 2,070 g/dL, quando aplicaram o método de imunodifusão radial, ressaltando o cuidado que se deve ter ao interpretar concentrações de imunoglobulinas obtidas por diferentes técnicas. Segundo os autores, a eletroforese em gel de acrilamida propicia o fracionamento mais acurado de proteínas, sendo mais específica na obtenção da fração IgG. Inclusive, Feitosa et al. (2001) observaram valores superestimados de concentrações de imunoglobulinas utilizando-se as provas de turbidimetria pelo sulfato de zinco e imunodifusão radial, justificando o ocorrido ao fato das amostras de soro possuírem grandes concentrações de IgG. Por conta disso, não existe um valor universalmente aceito da concentração sérica de IgG que caracterize a adequada transferência de imunidade.

Estudos descreveram correlação positiva e altamente significativa entre os valores de proteína total e gamaglobulinas, em recém-nascidos, demonstrando que a determinação da PST é um método eficaz de avaliação indireta da aquisição de imunidade passiva, na ausência de desidratação (FEITOSA et al., 2001; PAULETTI et al., 2002; SIMÕES et al., 2005; YANAKA et al., 2012).

Entretanto, existe discordância entre autores quanto à definição de um valor ideal de PST que confira uma adequada imunidade. Em bezerros, Costa et al. (2007) consideraram a ocorrência de falha de transferência de imunidade passiva (FTIP) nos animais que após a ingestão do colostro, possuíram PST inferior a $5 \mathrm{~g} / \mathrm{dL}$. Já em cordeiros, Costa et al. (2013) relataram FTIP quando os valores de PST foram menores ou iguais a $4,5 \mathrm{~g} / \mathrm{dL}$, no período de 24 a 72 horas de vida.

Neste trabalho, o menor valor de PST observado no $\mathrm{G} 1$ foi de $5,92 \mathrm{~g} / \mathrm{dL}$ e no $\mathrm{G} 2$ foi de $7,58 \mathrm{~g} / \mathrm{dL}$, às 24 horas de vida. Sendo assim, os dois tipos de manejo adotados foram eficientes para promover a adequada transferência de imunidade. Quando se comparou os resultados de PST entre os grupos (Tabela 1), observou-se diferenças significativas em 24 horas, sete e 15 dias de idade. Já ao nascimento e com 30 dias, os valores de PST foram estatisticamente semelhantes, assim como ocorreu para GLOB em todos os momentos observados. Quanto aos valores de ALB, só ocorreu diferença significativa entre os grupos aos sete dias de vida.

Para o G1, a transfererência de imunidade passiva também pôde ser constatada a partir dos testes de imunodiagnóstico para LVPR, que demonstraram a aquisição de imunoglobulinas colostrais (Figura 1). Antes da ingestão do pool de colostro de cabras positivas, os cordeiros estavam soronegativos nas provas de IDGA, Elisa e IB. Após 24 horas do nascimento, todos os animais foram reagentes nos três testes, permanecendo assim até os 50 dias de vida pela técnica de Elisa e IB. Resultados negativos começaram a ser observados, pela prova de IDGA, a partir dos 15 dias de idade e somente um dos nove cordeiros foi reagente aos 50 dias. Aos 70 dias, apenas o IB foi capaz de detectar anticorpos colostrais anti-LVPR e aos 90 e 120 dias, todos os cordeiros estavam soronegativos pelas três técnicas empregadas. 
Figura 1. Resultados dos testes de imunodifusão em gel de agarose (IDGA), ensaio imunoadsorvente ligado à enzima (Elisa) e immunoblotting (IB), do nascimento aos 120 dias de idade, de nove cordeiros que mamaram pool de colostro de cabras positivas para lentivírus de pequenos ruminantes (G1).

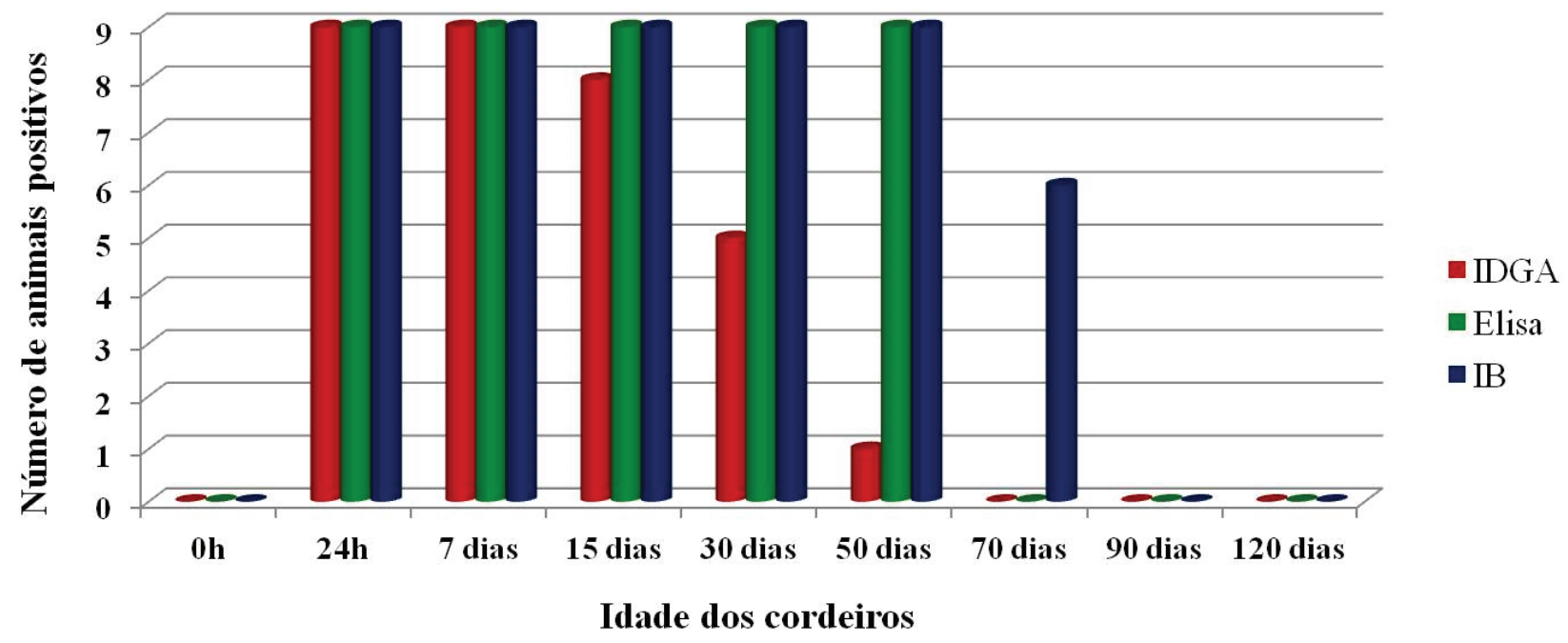

Fonte: Elaboração dos autores.

A ocorrência de resultados sorológicos negativos, inicialmente pela prova de IDGA, após o período de positividade, reflete a degradação das imunoglobulinas adquiridas passivamente (PAULETTI et al., 2002; FÉRES et al., 2010). Isto está de acordo com a meia-vida de uma a três semanas da $\mathrm{IgG}$, a imunoglobulina predominante no colostro de ruminantes (CERVENAK; KAVSKOVICS, 2009; HURLEY; THEIL, 2011). Em cabritos, verificou-se a menor concentração de IgG colostral aos 75 dias de vida (YANAKA et al., 2012). Logo, por conta do declínio na concentração das imunoglobulinas colostrais, somente os testes de Elisa e IB foram capazes de detectar anticorpos anti-LVPR por mais tempo, por serem mais sensíveis.

Em relação ao G2, constituído por cordeiros que mamaram colostro naturalmente de suas mães negativas, todos os animais apresentaram resultados negativos nos testes de IDGA e IB, do nascimento aos 120 dias de vida (Figura 2). Entretanto, soros reagentes foram constatados nas provas de Elisa às 24h, sete e quinze dias pós-nascimento. Curiosamente, nestes mesmos momentos, reações inespecíficas foram detectadas nos testes de IDGA, que apresentaram linhas sem identidade e nos testes de IB, que revelaram reações não relacionadas às proteínas dos LVPR. Por conta disso, julgouse os resultados positivos no Elisa como falsopositivos, oriundos de reações inespecíficas, com alta densidade óptica e consequentemente, com percentuais de positividade acima do ponto de corte estabelecido.

Celer Júnior et al. (1998) ressaltaram que o antígeno produzido a partir da partícula viral completa, como o utilizado neste trabalho, aumenta a sensibilidade da prova, entretanto, proteínas nãovirais constituintes do antígeno e oriundas do cultivo celular propiciam a ocorrência de resultados falsopositivos no Elisa. Ademais, deve-se considerar que as imunoglobulinas colostrais refletem o histórico de resposta do sistema imunológico da fêmea à exposição a diversos antígenos ao longo de sua vida (HURLEY; THEIL, 2011). Logo, a ocorrência das reações inespecíficas relatadas justifica-se pela tamanha variedade de epitopos que podem ser reconhecidos pelos anticorpos adquiridos passivamente. 
Figura 2. Resultados dos testes de imunodifusão em gel de agarose (IDGA), ensaio imunoadsorvente ligado à enzima (Elisa) e immunoblotting (IB), do nascimento aos 120 dias de idade, de dez cordeiros que mamaram colostro naturalmente de suas mães negativas para lentivírus de pequenos ruminantes $(\mathrm{G} 2)$.

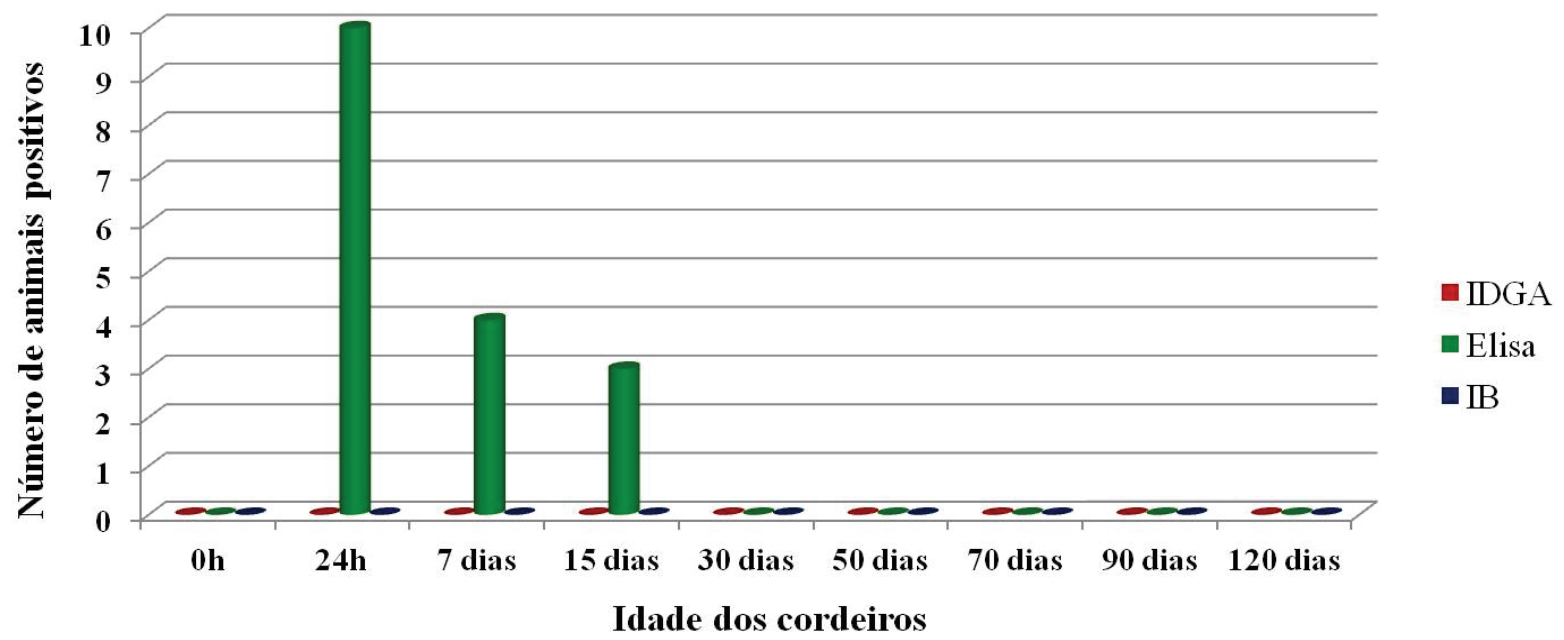

Fonte: Elaboração dos autores.

Comparações foram feitas entre os resultados obtidos pelas técnicas de IDGA, Elisa e IB (Tabelas 2 e 3). Apesar de muitos trabalhos adotarem o IDGA como padrão na determinação dos valores epidemiológicos relativos (LARA et al., 2002; REISCHAK; RAVAZZOLO; MOOJEN, 2002; DANTAS et al., 2008; TORRES et al., 2009), optouse neste estudo pela técnica de IB, que é a prova imunodiagnóstica mais próxima do "padrão ouro" para LVPR (PINHEIRO et al., 2011; SOUZA et al., 2012; LIMA et al., 2013; PINHEIRO et al., 2012).

Tabela 2. Indicadores epidemiológicos do teste de imunodifusão em gel de agarose (IDGA), para detecção de anticorpos contra lentivírus de pequenos ruminantes, em cordeiros, do nascimento aos 120 dias de idade, utilizando-se como padrão o immunoblotting (IB).

\begin{tabular}{lccc}
\hline Resultados & \multicolumn{2}{c}{ Resultados IB } & \multirow{2}{*}{ Totais } \\
\cline { 2 - 3 } \multicolumn{1}{c}{ IDGA } & Positivo & Negativo & \\
\hline Positivo & 32 & 0 & 32 \\
Negativo & 19 & 120 & 139 \\
Totais & 51 & 120 & 171 \\
\hline
\end{tabular}

Sensibilidade relativa: 63\%; especificidade relativa: $100 \%$; valor preditivo positivo: $100 \%$; valor preditivo negativo: $86 \%$; acurácia: 89\%; kappa: 0,70. Qui quadrado (corrigido por Yates): $88,55(\mathrm{p}<0,001)$.

Fonte: Elaboração dos autores.
Tabela 3. Indicadores epidemiológicos do ensaio imunoadsorvente ligado à enzima (Elisa), para deteç̧ão de anticorpos contra lentivírus de pequenos ruminantes, em cordeiros, do nascimento aos 120 dias de idade, utilizando-se como padrão o immunoblotting (IB).

\begin{tabular}{lccc}
\hline \multirow{2}{*}{$\begin{array}{c}\text { Resultados } \\
\text { Elisa }\end{array}$} & \multicolumn{2}{c}{ Resultados IB } & \multirow{2}{*}{ Totais } \\
\cline { 2 - 3 } & Positivo & Negativo & \\
\hline Positivo & 45 & 17 & 62 \\
Negativo & 06 & 103 & 109 \\
Totais & 51 & 120 & 171 \\
\hline
\end{tabular}

Sensibilidade relativa: $88 \%$; especificidade relativa: $86 \%$; valor preditivo positivo: $73 \%$; valor preditivo negativo: $94 \%$; acurácia: 87\%; kappa: 0,70. Qui quadrado (corrigido por Yates): $81,78(\mathrm{p}<0,001)$.

Fonte: Elaboração dos autores.

A menor sensibilidade foi observada para a técnica de IDGA e pode ser explicada pelos mecanismos de interação antígeno-anticorpo. Enquanto os testes imunoenzimáticos requerem a interação de apenas um epitopo por anticorpo para obter um resultado positivo, o teste de IDGA requer várias destas interações (CELER JÚNIOR et al., 1998). Isto aumenta a sua especificidade, mas diminui a sua capacidade em detectar animais positivos.

Já a maior sensibilidade do Elisa favorece a 
detecção de anticorpos, conforme também foi demonstrado por Lara et al. (2002), Cortez-Moreira, Oelemann e Lilenbaum (2005), Dantas et al. (2008), Cruz et al. (2009), Torres et al. (2009), Sardi et al. (2012) e Lima et al. (2013). Entretanto, resultados falso-positivos podem ocorrer, devido ao seu baixo valor preditivo positivo. Tanto o IDGA quanto o Elisa apresentaram concordância substancial com o IB, de acordo com parâmetros adotados por Thrusfield (2004).

A técnica de IB é a que apresenta maior sensibilidade e especificidade, se comparada ao Elisa e IDGA, sendo indicada como prova confirmatória para o diagnóstico de LVPR (CRUZ et al., 2003). Isso se deve à interpretação baseada em reações específicas às proteínas virais e à sua capacidade de detectar positividade em animais com baixos títulos de anticorpos anti-LVPR (PINHEIRO et al., 2012), conforme foi retratado neste estudo.

\section{Conclusões}

A partir dos resultados expostos, concluiu-se que aos 90 dias de vida, anticorpos colostrais antiLVPR não mais são detectados no soro de cordeiros. Logo, as técnicas de IDGA, Elisa e IB podem ser aplicadas após este período visando o diagnóstico. Ademais, frente às recentes pesquisas acerca da heterogeneidade dos LVPR e considerando que os anticorpos colostrais não previnem a infecção, outras análises serão necessárias para avaliar a ocorrência de transmissão interespécies, bem como a soroconversão desses animais e manfestação da doença.

\section{Agradecimentos}

À Fundação de Amparo à Pesquisa do Estado da Bahia (Fapesb) pelo fomento ao projeto e concessão de bolsa de doutorado, ao Conselho Nacional de Desenvolvimento Científico e Tecnológico (CNPq) pelo financiamento à pesquisa e a Embrapa Caprinos e Ovinos pelo apoio à execução do experimento.

\section{Referências}

ABREU, S. R. O.; CASTRO, R. S.; NASCIMENTO, S. A.; SOUZA, M. G. Produção de antígeno nucleoprotéico do vírus da artrite-encefalite caprina e comparação com o do vírus Maedi-Visna para utilização em teste de imunodifusão em ágar gel. Pesquisa Veterinária Brasileira, Seropédica, v. 18, n. 2, p. 57-60, 1998.

ÁlVAREZ, V.; ARRANZ, J.; DALTABUIT-TEST, M.; LEGINAGOIKOA, I.; JUSTE, R. A.; AMORENA, B.; ANDRÉS, D. de; LUJÁN, L. L.; BADIOLA, J. J.; BERRIATUA, E. Relative contribution of colostrum from Maedi-Visna virus (MVV) infected ewes to MVVseroprevalence in lambs. Research in Veterinary Science, Oxford, v. 78, n. 3, p. 237-243, 2005.

ÁlVAREZ, V.; DALTABUIT-TEST, M.; ARRANZ, J.; LEGINAGOIKOA, I.; JUSTE, R. A.; AMORENA, B.; ANDRÉS, D. de; LUJÁN, L. L.; BADIOLA, J. J.; BERRIATUA, E. PCR detection of colostrum-associated Maedi-Visna virus (MVV) infection and relationship with ELISA-antibody status in lambs. Research in Veterinary Science, Oxford, v. 80, n. 2, p. 226-234, 2006.

BORGES, A. S.; FEITOSA, F. L. F.; BENESI, F. J.; BIRGEL, E. H.; MENDES, L. C. N. Influência da forma de administração e da quantidade fornecida de colostro sobre a concentração de proteína total e de suas frações eletroforéticas no soro sanguíneo de bezerros da raça Holandesa. Arquivo Brasileiro de Medicina Veterinária e Zootecnia, Belo Horizonte, v. 53, n. 5, p. 629-634, 2001.

CALLADO, A. K. C.; CASTRO, R. S.; TEIXEIRA, M. F. S. Lentivírus de pequenos ruminantes (CAEV e MaediVisna): revisão e perspectivas. Pesquisa Veterinária Brasileira, Seropédica, v. 21, n. 3, p. 87-97, 2001.

CELER JÚNIOR, V.; CELER, V.; NEMCOVÁ, H.; ZANONI, R. G.; PETERHANS, E. Serologic diagnosis of ovine lentiviruses by whole virus ELISA and AGID test. Journal of Veterinary Medicine, Malden, v. 45, n. 3, p. 183-188, 1998.

CERVENAK, J.; KACSKOVICS, I. The neonatal Fc receptor plays a crucial role in the metabolism of $\operatorname{IgG}$ in livestock animals. Veterinary Immunology and Immunopathology, Amsterdam, v. 128, n. 1-3, p. 171177, 2009.

CORTEZ-MOREIRA, M.; OELEMANN, W. M. R.; LILENBAUM, W. Comparison of serological methods for the diagnostic of caprine arthritis-encephalitis (CAE) in Rio de Janeiro, Brazil. Brazilian Journal of Microbiology, São Paulo, v. 36, n. 1, p. 48-50, 2005.

COSTA, J. N.; PEIXOTO, A. P. C.; KOHAYAGAWA, A.; SOUZA, T. S. Proteinograma sérico de bezerras da raça Holandesa do nascimento aos 150 dias de idade. Revista 
Brasileira de Saúde e Produção Animal, Salvador, v. 8, n. 4, p. 267-275, 2007.

COSTA, J. N.; SILVA, D. F. M.; LIMA, C. C. V.; SOUZA, T. S.; ARAÚJO, A. L.; COSTA NETO, A. O.; ALMEIDA, M. A. O. Falha da transferência de imunidade passiva em cordeiros mestiços (Santa Inês X Dorper) e estudo do proteinograma do nascimento até o desmame. Brazilian Journal of Veterinary Research and Animal Science, São Paulo, v. 50, n. 2, p. 114-120, 2013.

CRUZ, E. T.; GONZÁLEZ, R. H.; RODRÍGUEZ, A. M.; ÁlVAREZ, H. R.; ORTEGA, M. E. T.; SCHMID, R. K.; SETIÉN, A. A. Detección de anticuerpos contra artritis encefalitis caprina (AEC) mediante inmunoelectrotransferencia. Veterinária México, Ciudad Universitaria, v. 34, n. 2, p. 119-127, 2003.

CRUZ, R. B.; PUTINI, V. B.; SANTANA, G. S.; JORGE, J. S.; COELHO, I.; SILVA, D. L.; ZACHARIAS, F.; TIGRE, D.; CERQUEIRA, R. B. Estudo comparativo da sensibilidade e da especificidade de ELISA indireto com o teste de imunodifusão em gel de agarose no diagnóstico da artrite-encefalite caprina (CAEV). Revista Acadêmica de Ciências Agrárias e Ambientais, São José dos Pinhais, v. 7, n. 3, p. 355-364, 2009.

DANTAS, T. V. M.; ARAÚJO, S. A. C.; PINHEIRO, R. R.; ARAGÃO, M. A. C.; SILVA, J. B. A.; RICARTE, A. R. F.; RIBEIRO, A. L.; TEIXEIRA, M. F. S. Desenvolvimento e padronização de um ELISA indireto para diagnóstico de maedi visna em ovinos. Ciência Animal Brasileira, Goiânia, v. 9, n. 1, p. 181-187, 2008.

DAWSON, M. Caprine arthritis-encephalitis. In Practice, London, v. 9, n. 1, p. 8-11, 1987.

FEITOSA, F. L. F. Importância da transferência da imunidade passiva para a sobrevivência de bezerros neonatos. Revista de Educação Continuada CRMV-SP, São Paulo, v. 2, n. 3, p. 17-22, 1999.

FEITOSA, F. L. F.; BIRGEL, E. H.; MIRANDOLA, R. M. S.; PERRI, S. H. V. Diagnóstico de falha de transferência de imunidade passiva em bezerros através da determinação de proteína total e de suas frações eletroforéticas, imunoglobulinas $\mathrm{G}$ e $\mathrm{M}$ e da atividade da gama glutamiltransferase no so sanguíneo. Ciência Rural, Santa Maria, v. 31, n. 2, p. 251-255, 2001.

FÉRES, F. C.; LOMBARDI, A. L.; BARBOSA, T. S.; MENDES, L. C. N.; PEIRÓ, J. R.; CADIOLI, F. A.; PERRI, S. H. V.; FEITOSA, F. L. F. Avaliação da transferência de imunidade passiva em cordeiros com até 30 dias de idade. Brazilian Journal of Veterinary Research and Animal Science, São Paulo, v. 47, n. 3, p. 231-236, 2010.

GENDELMAN, H. E.; NARAYAN, O.; KENNEDY-
STOSKOPF, S.; KENNEDY, P. G. E.; GHOTBI, Z.; CLEMENTS, J. E.; STANLEY, J.; PEZESHKPOUR, G. Tropism of sheep lentiviruses for monocytes: susceptibility to infection and virus gene expression increase during maturation of monocytes to macrophages. Journal of Virology, Washington, v. 58, n. 1, p. 67-74, 1986.

HURLEY, W. L.; THEIL, P. K. Perspectives on immunoglobulins in colostrum and milk. Nutrients, Basel, v. 3, n. 4, p. 442-474, 2011.

LARA, M. C. C. S. H.; BIRGEL JUNIOR, E. H.; FERNANDES, M. A.; BIRGEL, E. H. Infecção experimental do vírus da artrite-encefalite dos caprinos em cabritos. Arquivos do Instituto Biológico, São Paulo, v. 70, n. 1, p. 51-54, 2003.

LARA, M. C. C. S. H.; BIRGEL JUNIOR, E. H.; REISCHAK, D.; MOOJEN, V.; GREGORY, L.; OLIVEIRA, J. C. F.; BIRGEL, E. H. Identificação imuno-sorológica de anticorpos anti-vírus da artriteencefalite dos caprinos: comparação das técnicas de imunodifusão em gel de ágar, ensaio imunoenzimático e imunofluorescência indireta. Arquivos do Instituto Biológico, São Paulo, v. 69, n. 4, p. 1-5, 2002.

LIMA, C. C. V.; COSTA, J. N.; SOUZA, T. S.; MARTINEZ, P. M.; COSTA NETO, A. O.; AZEVEDO, D. A. A.; PINHEIRO, R. R.; BRITO, R. L. L. Imunodiagnóstico para a artrite-encefalite caprina em rebanhos do semiárido baiano, Brasil. Revista Brasileira de Medicina Veterinária, Rio de Janeiro, v. 35, n. 4, p. 358-364, 2013.

MUKHERJEE, R. Selenium and vitamin E increases polymorphonuclear cell phagocytosis and antioxidant levels during acute mastitis in riverine buffaloes. Veterinary Research Communication, Nova Iorque, v. 32, n. 4, p. 305-13, 2008.

NÓBREGA JÚNIOR, J. E.; RIET-CORREA, F.; NÓBREGA, R. S.; MEDEIROS, J. M.; VASCONCELOS, J. S.; SIMÕES, S. V.; TABOSA, I. M. Mortalidade perinatal de cordeiros no semi-árido da Paraíba. Pesquisa Veterinária Brasileira, Seropédica, v. 25, n. 3, p. 171178, 2005.

OLIVEIRA, M. M. M.; MELO, M. A.; ANDRADE, P. P.; GOMES, S. M.; CAMPOS, A. C.; NASCIMENTO, S. A.; CASTRO, R. S. Western Blot para o diagnóstico das infecções pelos lentivírus de pequenos ruminantes em caprinos: um método simples para a produção de antígeno. Arquivos do Instituto Biológico, São Paulo, v. 75, n. 3, p. 263-270, 2008.

PASICK, J. Maedi-Visna virus and caprine arthritisencephalitis virus: distinct species or quasispecies and its implications for laboratory diagnosis. Canadian Journal 
of Veterinary Research, Ottawa, v. 62, n. 4, p. 241-244, 1998.

PAULETTI, P.; MACHADO NETO, R.; PACKER, I. U.; BESSI, R. Avaliação de níveis séricos de imunoglobulina, proteína e o desempenho de bezerras da raça Holandesa. Pesquisa Agropecuária Brasileira, Brasília, v. 37, n. 1, p. 89-94, 2002.

PEIXOTO, A. P. C.; COSTA, J. N.; KOHAYAGAWA, A.; TAKAHIRA, R. K.; SAITO, M. E. Hemograma e metabolismo oxidativo dos neutrófilos de bovinos da raça Holandesa preta e branca - Influência dos fatores etários. Brasileira de Saúde e Produção Animal, Salvador, v. 3, n. 1, p. 16-20, 2002.

PINHEIRO, R. R.; ANDRIOLI, A.; GOUVEIA, A. M. G.; ARAGÃO, M. A. C.; MARTINEZ, P. M. Avaliação de antígenos para o diagnóstico de lentivírus em rebanho caprino sob programa de controle. Arquivos do Instituto Biológico, São Paulo, v. 77, n. 1, p. 133-137, 2010.

PINHEIRO, R. R.; ANDRIOLI, A.; SIDER, L. H.; SANTIAGO, L. B.; OLIVEIRA, E. L.; SOUSA, A. L. M.; ALVES, F. S. F.; CRUZ, J. C. M. Lentiviroses em pequenos ruminantes: principais métodos de diagnóstico. Sobral: Embrapa Caprinos e Ovinos, 2012. 42 p. (Documentos, 107).

PINHEIRO, R. R.; BRITO, R. L. L.; RODRIGUES, A. S.; DIAS, R. P.; ANDRIOLI, A.; GOUVEIA, A. M. G. Protocolo de immunoblotting para diagnóstico da artrite-encefalite caprina. Sobral: Embrapa Caprinos e Ovinos, 2011. 4 p. (Comunicado técnico, 122).

PINHEIRO, R. R.; GOUVEIA, A. M. G.; YORINORI, E. H.; ANDRIOLI, A. Comparação de três técnicas de produção do antígeno do lentivírus caprino utilizado no teste de imunodifusão em gel de ágar. Brazilian Journal of Veterinary Research and Animal Science, São Paulo, v. 42, n. 6, p. 453-458, 2005.

PINHEIRO, R. R.; OLORTEGUI, C. D. C.; GOUVEIA, A. M. G.; ARAÚJO, S. C.; ANDRIOLI, A. Desenvolvimento de dot-blot para detecção de anticorpos para o vírus da artrite-encefalite caprina em caprinos. Revista Portuguesa de Ciências Veterinárias, Lisboa, v. 101, n. 557-558, p. 51-56, 2006.

PREZIUSO, S.; RENZONI, G.; ALLEN, T. E.; TACCINI, E.; ROSSI, G.; DEMARTINI, J. C.; BRACA, G. Colostral transmission of Maedi-visna virus: sites of viral entry in lambs born from experimentally infected ewes. Veterinary Microbiology, Barcelona, v. 104, n. 3-4, p. 157-164, 2004.

REISCHAK, D.; RAVAZZOLO, A. P.; MOOJEN, V. Imunofluorescência utilizando isolados brasileiros no diagnóstico sorológico de infecção por lentivírus em caprinos. Pesquisa Veterinária Brasileira, Seropédica, v. 22, n. 1, p. 7-12, 2002.

SARDI, S. I.; TORRES, J. A.; BRANDÃO, C. F. L.; TIGRE, D. M.; CAMPOS, G. S. Early detection of goats infected with lentivirus small ruminant virus by ELISA assay. Revista de Ciências Médicas e Biológicas, Salvador, v. 11, n. 1, p. 35-40, 2012.

SILVA, D. F. M.; COSTA, J. N.; ARAÚJO, A. L.; COSTA NETO, A. O.; ALMEIDA, M. A. O.; CARVALHO, V. S. Proteinograma sérico de cordeiros mestiços (Santa Inês X Dorper) do nascimento até o desmame: efeito do desenvolvimento etário e do monitoramento da ingestão do colostro. Ciência Animal Brasileira, Goiânia, v. 11, n. 4, p. 794-805, 2010.

SILVA, S. L.; FAGLIARI, J. J.; BAROZA, P. F. J.; CESCO, F. T. R. S.; JORGE, R. L. N. Avaliação da imunidade passiva em caprinos recém-nascidos alimentados com colostro de cabras ou colostro de vacas. ARS Veterinária, Jaboticabal, v. 23, n. 2, p. 81-88, 2007.

SIMÕES, S. V. D.; COSTA, R. G.; SOUZA, P. M.; MEDEIROS, A. N.; VILAR, A. L. T. Imunidade passiva, morbidade neonatal e desempenho de cabritos em diferentes manejos de colostro. Pesquisa Veterinária Brasileira, Seropédica, v. 25, n. 4, p. 219-224, 2005.

SOUZA, T. S.; PINHEIRO, R. R.; LIMA, C. C. V.; COSTA, J. N. Transmissão interespécie dos lentivírus de pequenos ruminantes: revisão e desafios. Acta Veterinaria Brasilica, Mossoró, v. 6, n. 1, p. 23-34, 2012.

STATISTICA version 7.1. Data analysis software system. Tulsa: StatSoft Inc., 2005. Disponível em: < www.statsoft. com>. Acesso em: 28 out. 2012.

STRAUB, O. C. Maedi-Visna virus infection in sheep. History and present knowledge. Comparative Immunology Microbiology \& Infectious Diseases, Philadelphia, v. 27, n. 1, p. 1-5, 2004.

THRUSFIELD, M. V. Epidemiologia veterinária. 2. ed. São Paulo: Roca. 2004. 556 p.

TORRES, J. A.; CAMPOS, G. S.; FREITAS, M. M.; BRANDÃO, C. F. L.; SARDI, S. I. Produção de antígeno viral para o diagnóstico da artrite-encefalite caprina utilizando um teste imunoenzimático (ELISA). Revista de Ciências Médicas e Biológicas, Salvador, v. 8, n. 2, p. 107-114, 2009.

YANAKA, R.; CAMARGO, D. G.; BOVINO, F.; SANTOS, W. A.; DÓCUSSE, M. R.; CAVASSANO, B. S.; FEITOSA, F. L. F. Período de absorção intestinal de macromoléculas em cabritos recém-nascidos após a ingestão de colostro bovino. Pesquisa Veterinária Brasileira, Seropédica, v. 32, n. 8, p. 794-802, 2012. 
